\title{
PESQUISAS SOBRE CURRÍCULOS, GÊNEROS E SEXUALIDADES
}

\author{
Anderson Ferrari ${ }^{(*)}$ \\ Danilo Araujo de Oliveira ${ }^{(*)}$
}

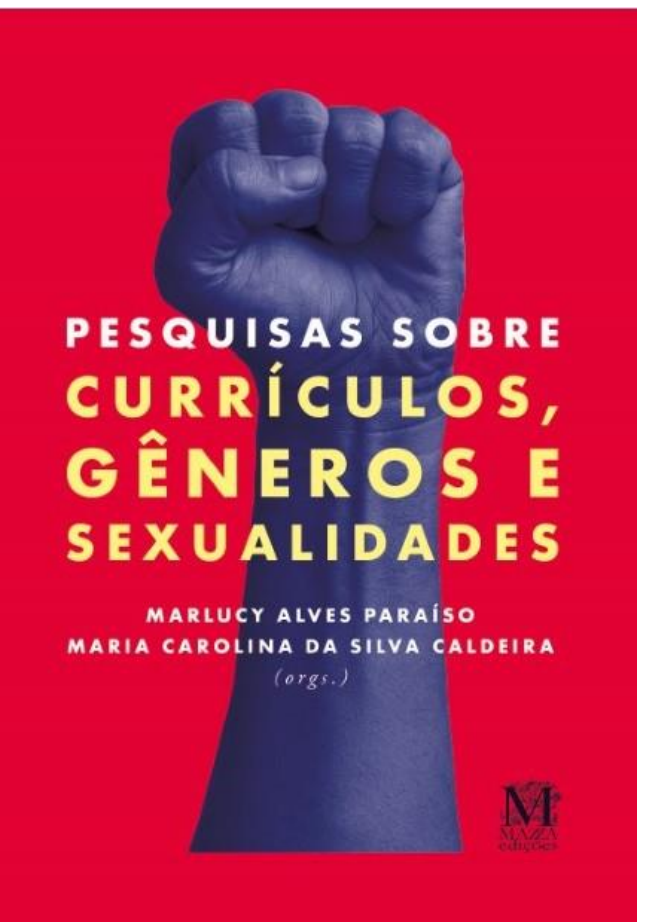

PARAÍSO, Marlucy Alves; CALDEIRA, Maria Carolina da Silva (Org.). Pesquisas sobre currículos, gêneros e sexualidades. Belo Horizonte: Mazza, 2018.

É dedicando o livro as "pessoas que lutam, de diferentes modos, contra os modelos excludentes que não lhes cabem", que Marlucy Alves Paraíso e Maria Carolina da Silva Caldeira nos brindam com os capítulos que compõem Pesquisas sobre Currículos, Gêneros e Sexualidades. Uma coletânea que reúne autoras e autores que "lutam" contra esses modelos excludentes, que sustentam a luta por meio das suas pesquisas e escritas e nos armam com os deslocamentos que provocam nos currículos, nos gêneros e nas sexualidades, nos ensinando que esses são territórios móveis, fluídos e em construção. Estão presentes dois campos de conhecimento - Currículo e as Relações de Gênero e Sexualidade - que são recentes, potentes, ameaçadores e ameaçados. Dois campos que se cruzam constantemente e, que cada vez mais, necessitam de obras como esta em que dialogam, demonstrando que gênero e sexualidade organizam os currículos e,

\footnotetext{
${ }^{(*)}$ Professor do PPGE da Universidade Federal de Juiz de Fora (UFJF) Mestrado e Doutorado. E-mail: aferrari13 @globo.com.

${ }^{(* *)}$ Doutorando do PPGE da Universidade Federal de Minas Gerais (UFMG). E-mail: danilodinamarques@hotmail. com.
} 
que estes, por sua vez, participam das construções e desconstruções das relações de gênero e sexualidade.

Uma obra necessária para o momento atual que nos convoca a pensar a relação dos sujeitos com os corpos, com as relações de gênero e com as sexualidades, alvos de ataques das forças conservadoras. Podemos pensar que historicamente, os enquadramentos tomavam os corpos, os gêneros e as sexualidades dos sujeitos, aprisionando-os e isso se dava por diferentes mecanismos, dentre eles, os currículos, as escolas, os sistemas educacionais disciplinadores. Mas nesses aprisionamentos também residiam as liberdades e as resistências, de maneira que currículos, gêneros e sexualidades podem ser pensados como marcados por paradoxos. Não é por acaso que os sujeitos se rebelaram e no interior desse paradoxo encontraram brechas, espaços de fugas para minar esses aprisionamentos e explorar novas formas de conhecer. Sujeitos que estão presentes no livro, seja como autoras e autores ou como participantes das pesquisas que dão consistência as reflexões. "Tormentas", "resistências criativas", "territórios disputados”, “diferença", "invenção política", são algumas das palavras que povoam os textos. Mais do que palavras, são promessas de uma escrita problematizadora, interessada nos encontros entre currículos, gêneros e sexualidades como investimento em outra forma de pensar, saber, ser e estar no mundo. Palavras que atravessam o conjunto que compõem o livro, entendendo e apostando nos campos do currículo, dos gêneros e das sexualidades como espaços de luta, de disputa, que nos convocam, neste momento atual de ataque as conquistas alcançadas, a nos armar para o enfrentamento. Nos armar no campo da pesquisa, na produção criativa da resistência. Se estamos em meio a jogos de força, a resistência é o que resta. Uma obra que anuncia que, em meio ao contexto político que estamos atravessando, na atualidade, é possível desenvolver estratégias de resistência, esperança e rupturas.

Feito de possibilidades, estranhamentos, tensionamentos, movimentos, resistências, desconstruções e multiplicidades, esse livro nos convida, desloca e provoca a expor formas e enquadramentos que retiram direitos de pessoas, atacam as políticas de igualdade de gênero e excluem as sexualidades subalternas que povoam o currículo.

Logo no primeiro capítulo, potentes descobertas e invenções vão de encontro aos movimentos reacionários aos estudos de gênero no currículo. O que em um primeiro olhar poderia tentar embargar as impetuosas discussões de gênero e sexualidade possibilitam um fluxo contrário. Nos disseram que temos que dançar conforme a música, mas aprendemos a ser desobedientes e a ousar. É esse descompasso à ideologia de gênero que Paraíso evidencia ao mostrar como duas professoras dançam com seus currículos, fazendo deles "um território de acolhimento, hospitalidade e expansão da diferença" (PARAÍSO, 2018, 37). 
Os investimentos em movimentos como os detalhados no primeiro capítulo são incessantes e surgem das mais variadas políticas de governo que tentam sugerir um currículo desinteressado às questões de gênero, conforme destaca Caldeira ao analisar práticas formativas de professoras alfabetizadoras que fazem funcionar as tecnologias de gênero por meio das técnicas do apagamento e da feminização. Dessa forma, essa discussão evidencia que o investimento em currículos desinteressados às questões de gênero também fomentam uma propagação de raciocínios binários, o que colabora para demandas de posições de sujeitos, que não pretendem alcançar somente os/as alunos/as, mas também as professoras que participam da formação.

Os textos demonstram como o currículo, como campo de conhecimento, está em meio a jogos de poder e relações de força que mantém a disputa, a negociação e o confronto que marcam sua prática e produção. Não por acaso, ao analisar Gênero nos currículos de formação docente em Educação Física no Brasil, Nicolino mostra como esse campo ainda carece de uma abordagem mais problematizadora do gênero. Tal abordagem nos convida a colocar sob suspeita os discursos que são autorizados e silenciados nos diferentes currículos das escolas brasileiras a partir dos livros didáticos. Inseridos na cultura escolar e amplamente utilizados, acabam funcionando como um importante artefato nos processos de subjetivação, pois fazem circular discursos de gênero e sexualidades, regulam sujeitos por meio de discursos atravessados por relações de poder interessados em propagar certos modos de viver que "por estar transvestido da roupagem científica, dá força de verdade e autoridade às diferenças biológicas, intelectuais e culturais" (CARDOSO, 2018, p. 109).

Diferentes artefatos se cruzam nessa empreitada em posicionar os sujeitos nos lugares reservados pelas normas de gêneros. Um exemplo disso são os livros de literatura infantil que compõe os kits de literatura afro-brasileira analisados no quinto capítulo entendidos como um meio de atualização da norma. As crianças são alvo de mecanismos regulatórios, os quais ditam lugares fixos que, de forma binária, anunciam corpos masculinos e femininos que se opõe, ainda que estejamos falando de um material que se propõe a ressignificação do ser negro/a e indígena. Esses mecanismos de controle para produção de dualismos e generificações se espalham e encontram diferentes formas de alcançar os sujeitos.

As "narrativas matemáticas" do sexto capítulo, nos contam sobre uma matemática que ainda é construída tendo como referência o masculino e a heteronormatividade, mas que também possibilita os sujeitos encontrarem formas de burlar suas regras sugerindo modos outros de existir. O desafio e a potencialidade do texto estão em nos fazer pensar em uma matemática que pode ser também das diversidades, de práticas plurais em diálogo com políticas de gênero e sexualidade. 
As pesquisas apresentadas, na sua totalidade, demonstram como o gênero é construído por ações que precisam ser reiteradas constantemente para ganharem efeito de verdade sobre os sujeitos. Assumindo essa concepção de gênero e sexualidade como construção performática que se reitera nas ações cotidianas os autores e as autoras se filiam as discussões mais atualizadas por autoras como Judith Butler e Paul Beatriz Preciado. Os diversos artefatos culturais problematizados evidenciam como as normas de gênero e a heterossexualidade circulam demandando um tipo de sujeito hegemônico e uma sexualidade construída como verdadeira e autorizada. As professoras alfabetizadoras e as crianças voltam à cena na pesquisa que discute o currículo dos blogs sobre alfabetização como alvo dessas construções que essencializam, naturalizam e dicotomizam os corpos, os sujeitos, ainda que haja algumas exceções a esse modelo posto. Mantendo a coesão entre os capítulos, podemos dizer que há um entendimento de que as relações de gênero são organizadoras sociais, atravessadas por saberes e relações de poder que nos constituem, de maneira que fazer de educação é dizer destes currículos que estão nos nossos cotidianos, são produzidos e produtores de sujeitos.

O capítulo intitulado A problematização em Foucault como ferramenta para analisar projetos de futuro de jovens estudantes: intersecções entre gênero e currículo, tenciona aquilo que comumente chamamos de juventude, nos convidando a olhar essa categoria pelos seus múltiplos aspectos de vivência e provocados pelos atravessamentos de gênero, raça/etnia e classe social. A pesquisa chama atenção para um projeto de futuro presente no currículo pesquisado que não dá conta de tantas diferenças intrínsecas ao ser jovem no Brasil, mas que regula, controla e disciplina.

Essas multiplicidades de ser jovem, de ser aquilo que não cabe em um currículo prescritivo e regulador, também trazem toda a criatividade, inventividade para o currículo, multiplicando de forma forte e contundente as formas de vida que são possíveis ao currículo. Ao dançar, desfilar e performatizar, as histórias dos jovens gays que Thiago Raniery traz para seu texto, retomam o que Paraíso diz na abertura do livro que "dançar é sair do lugar, movimentar a si mesmo e as coisas, sorrir com o corpo, entrar em um ritmo, inventar movendo-se" (PARAISO, 2018, p. 23). E se anteriormente falávamos de um currículo que tem um projeto de futuro para um certo jovem, estamos falando em "condições de viver exposto à morte social ou física para quem o futuro não é uma certeza, pois sabem bem o impacto que formas ignóbeis de obliteração da subsistência têm sobre suas vidas" (RANNIERY, 2018, p. 209).

A potência da música e da dança é retomada no capítulo dez que animam nossa leitura e perspectivas de um currículo que pode ser habitado por alegria e movimentos, ainda que haja um interesse hegemônico em usar elementos como música e dança para normalizar os corpos que 
transitam ali. A preparação para uma festa junina é marcada por ensaios que buscam ensinar meninos e meninas a ocuparem espaços generificados. Nesses processos vão sendo colocados em ação diferentes correções, regulações e discursos. Ações constantes e discursos heteronormativos que atravessam os investimentos nesse currículo, mas mesmo assim, os corpos escapam, questionam e parecem esquecer. As subversões e resistências vêm à tona e embaralham o que estava posto como correto e natural.

A discussão sobre sexualidade e infância é retomada em mais de um capítulo. Mantendo uma coerência de perspectiva teórico-metodológica, eles questionam os saberes que as alcança, permitindo que as crianças desde pequenas identifiquem modos considerados adequados de ser homem e ser mulher (e também brinquem com esses saberes). Os discursos sobre anormalidade ainda é um peso que se incide sobre os corpos infantis, de maneira que as práticas pedagógicas são de correção e de vigilância ainda que nada garanta que esse objetivo seja alcançado, que isso seja um sucesso (e não é). O capítulo seguinte anuncia toda essa ousadia da infância em deturpar aquilo que o currículo da escola pesquisada quer garantir, crianças conformadas às normas de gênero e sexualidade.

Nos deparamos, então, com crianças que chegam "tombando" com as prescrições, arriscando modos de viver que não são ensinados como correto, mobilizam forças, formam grupos que vão na contramão do controle, separação, hierarquização que essa escola promove. A leitura nos questiona, nos faz sonhar, ver possibilidades de esperança por um currículo que se deixa envolver pelas forças que bagunçam aquilo que está posto e naturalizado.

As normas se atualizam e encontram formas de agir e alcançar os indivíduos por diferentes aparatos, considerando que vivemos num mundo onde as novas tecnologias digitais alteraram os sentidos e modos de existir. O capítulo 13 traz as contestações do currículo da nudez à dominação vigente compartilhando uma subversão reinventada e reatualizada. É um trabalho inovador para pensar os processos de subjetivação de mulheres em ambientes virtuais, o corpo nu fotografado tensiona discursos e trazem reividincações políticas para esse artefato cultural.

Tomando um site de relacionamento como foco de investigação, as autoras do capítulo 14 promovem um encontro do/da leitor/a com esse currículo marcado pelo desejo, processos de subjetivação e também atravessado por normas. Uma tecnologia que coloca em funcionamento modos de ser lésbica. No entanto, essas mulheres se aproximam e se distanciam de modos diferenciados dessas aprendizagens burlando as regras e modos colocados como correto nesse espaço, reiventando modos de viver a sexualidade "como a de se viver o prazer dentro do armário" 
(RIBEIRO; FONSECA, p. 320). Ao questionar a caracterização da homossexualidade, elas celebram as diferenças.

Corpo em trânsito e desterritorialização de gênero no currículo da cidade com a arte é vibrante, nos empolga pelas múltiplas possibilidades de um corpo não marcado pela norma, um corpo em prática de liberdade, inventivo e fluido. É desafiador ler e perceber que é possível fugir dos enquadramentos e experimentar aquilo que até parece inconcebível para os espaços que transitamos em nossos percursos formativos, como a escola e outros espaços de sociabilidade, por exemplo. O trabalho coloca em circulação o debate de um currículo que pode assumir outras formas, constituído de vidas vivíveis, que rompe com o controle, um currículo alegre e entre tantas outras provocações ainda nos chama atenção para observar os corpos que povoam as cidades, como corpos políticos, encontros esses que dizem do encontro com (des)aprendizagens sobre normas de gênero e sexualidades.

Chegando ao último capítulo do livro, o trabalho potencializa o currículo do cinema como espaço educativo, percebido como uma pedagogia cultural, espaço de aprendizagens permeado por relações de saber, poder interessados em produzir sujeitos. O destaque reservado a contextualizar o trabalho, mostra como as grandes produções do cinema brasileiro ainda reproduzem discursos hegemônicos normativos, modelos de masculinidade e reforçam a subalternidade feminina. Mas esse artigo foca as produções do cinema que são subversivas como um currículo que deseja vidas das mais diferentes formas, distantes dos estereótipos, colocando na tela "a potência do desejo e a inconformidade com aquilo que nos oprime" (FILHO; MAKNAMARA, 2018, p. 360).

Esse livro vem como resistências, invenções, provocações, afirmando que podemos ir além das barreiras que nos são impostas, potencializa as discussões de gênero e sexualidades com nossos/as alunos, evidencia diferentes artefatos estão aí para nos mostrar de quantas vidas que há em meio a esses desmontes. Discutir processos de subjetivação a partir de diferentes olhares, lugares e perspectivas do currículo nos empodera e nos enche de ferramentas, armas para ir em frente, para enfrentar, combater aquilo que nos entristece, evidenciando aquilo que alegra e deixa o currículo povoado de diferentes formas de viver e formas inéditas de vida. 


\section{RESUMO}

A resenha pretende trazer para o leitor as pesquisas reunidas nesse livro que, de forma geral, problematizam diferentes currículos a partir de múltiplos enfoques, campos e olhares. Currículo escolar, do livro didático, dos blogs, dos filmes, de sites de relacionamentos, políticas de formação docente, literatura, música, se encontram aqui para nos fazer pensar modos diversos nos processos de subjetivação, nas normas de gênero e sexualidades que atravessam esses artefatos, mas, sobretudo, para evidenciar possibilidades de escape, ruptura e resistência. Pesquisas situadas na perspectiva teórica pós-crítica.

\section{ABSTRACT}

The review intends to bring to the reader the research gathered in this book that, in general, problematizes different curricula from multiple focuses, fields and looks. School curricula, textbooks, blogs, movies, social networking sites, teacher education policies, literature, music, are here to make us think of different ways in the processes of subjectivation, gender norms and sexualities that cross these artifacts, but, above all, to show possibilities of escape, rupture and resistance. Research in the post-critical theoretical perspective.

\section{RESUMEN}

La reseña pretende traer al lector las investigaciones reunidas en ese libro que, en general, problematizan diferentes currículos a partir de múltiples enfoques, campos y miradas. Currículo escolar, del libro de texto, de los blogs, de las películas, de los sitios de relaciones, las políticas de formación docente, literatura, música, se encuentran aquí para hacernos pensar modos diversos en los procesos de subjetivación, en las normas de género y sexualidades que atraviesan esos artefactos, pero, sobre todo, para evidenciar posibilidades de escape, ruptura y resistencia. Investigaciones situadas en la perspectiva teórica post-crítica. 